\title{
Developing Value Framework of Ubiquitous Computing
}

\author{
Jungwoo Lee, Younghee Lee, and Jaesung Park \\ Graduate School of Information, Yonsei University \\ Sudaemun Gu, Shinchon Dong 134, Seoul, Korea \\ \{jlee, rarayes\} @yonsei.ac.kr, tomypink@hotmail.com
}

\begin{abstract}
In this study, a value framework for ubiquitous computing is developed and presented. Using 'value focused thinking' approach suggested by Keeney, twenty-two potential users of ubiquitous computing were interviewed and 435 statements describing values expected from ubiquitous technology were obtained from these interviews. Subsequent purification and redundancy removal reduces these 435 statements into 166 objectives that these users have in their mind when thinking about ubiquitous computing. These 166 objectives were factorized into 35 objectives through clustering by three experts. These 35 objectives were classified into a means-ends network diagram by analyzing reciprocal relationships among them in a focus group activity of another three experts. Resulting means-ends network reveals a value framework inherent in users' perception about ubiquitous computing technologies. This framework will be useful as a reference in developing new business models for ubiquitous computing as well as developing useful technologies themselves.
\end{abstract}

Keywords: Ubiquitous Computing, user's values, value-focused thinking, value framework, means-ends network.

\section{Introduction}

Since Mark Weiser termed 'ubiquitous' as a new paradigm for computing in 1988, efforts have been concerted to develop and advance information technologies towards 'connecting, invisible calm and silent, and real' ubiquitous computing [1]. Recently, efforts have been concerted to develop ubiquitous technologies such as RFID and to standardize interfaces and communications such as EPC Networks, in order to expedite the adoption of ubiquitous computing in the real world. Ubiquitous computing is now considered to be the technology critical not only for the support of businesses, but also as an enabler of strategic positioning of businesses [2,3].

However, despite good progresses made in the ubiquitous technology itself and high public expectations generated from popular movies and dramas, practitioners are still struggling over what are the appropriate business models which may provide incredible value as a new ubiquitous businesses [4]. In this regard, questions still remained unanswered about real and practical values provided by ubiquitous computing. What are the real and practical offerings of ubiquitous computing to users and businesses? 
In this context, this research is purported to elicit values expected from the users' side about how ubiquitous computing technology would benefit their life and work, and present these values as a value framework so that further technological and business development can be assessed against this value framework.

\section{Research Method}

This study is methodologically based on 'value focused thinking (VFT)' approach [5] This VFT approach consists of four steps designed to elicit and frame values: (1) conduct interviews and construct a list of what they want in the decision context, (2) convert these statements into a common format of objectives (an object and a preference), and (3) purify and cluster these objectives into a more general and simpler set of fundamental objectives and means objectives, and (4) establish means-ends network of these objectives so that fundamental objective values can be identified with instrumental values to leading to these fundamental values.

In the context of this research, this four-step method is applied in order to assess values attached, by users, to ubiquitous computing. Twenty two users were interviewed. Twelve were graduate students while ten were practitioners in the field. At the beginning of each interview, three scenarios of ubiquitous environment were explained in detail: a news service on a personal digital assistant, an intelligent refrigerator informing the owner about the status of food in it, and an automatic gate keeper recognizing authorized persons automatically. Subjects were already familiar with these scenarios through public media. Table 1 summarizes details of the research methodology.

Table 1. Research methodology

\begin{tabular}{l|l}
\hline Question & What are the values of ubiquitous computing to users? \\
\hline Strategy & Case study. \\
\hline Paradigm & Interpretive (value focused thinking). \\
\hline $\begin{array}{l}\text { Data } \\
\text { collection }\end{array}$ & Dialogue; in-depth interviews. \\
\hline References & Keeney [5-7], Torkzadeh [8] \\
\hline Informants & Users of ubiquitous computing \\
\hline Type of results & $\begin{array}{l}\text { Wish list, means-fundamental objectives network, in-depth } \\
\text { predictive description. }\end{array}$ \\
\hline
\end{tabular}

Construct a wish list from each interview. Users' values were found out by a dialogue with triggering questions. As, in many cases, users' values are hidden under the surface, Keeney recommends several stimulation techniques to surface these latent values. We chose a combination of two techniques: wish list and probing. First, each interviewee was asked to express what benefits and services that they expect from ubiquitous computing technologies, as many as possible. Whenever subjects are having problem articulating what they want, interviewer posed probing questions mostly by adding why and how to the statements that they were making. Twenty two 
interviews generated 298 initial wish statements and 137 additional statements triggered by probing questions, totaling 435 statements.

Convert statements into objectives. These statements are converted into objectives, using an action verb plus an object so that directions of wanted changes and target of change are more clearly and directly stated. Some statements were compound sentences, which contain more than one objective and these statements were divided into simpler ones. Some statements were ambiguous and in which case, interviewee were recalled and asked triggering questions again through phone calls. In this clarification process, two researchers were involved in reviewing each item on the list independently. Through this review process, a list of 166 objectives was finalized.

Purify and cluster these objectives into a simpler set. In using ubiquitous computing, users wanted to achieve these 166 objectives. However, these objectives are not properly articulating values yet, and also duplication can be found. The objectives were then categorized in order to surface the latent meanings and more general values attached to ubiquitous computing. Categorization by three expert focus group activities produced 35 value statements as shown in table 2 .

Table 2. Means Objectives and End Objectives

\begin{tabular}{ll}
\hline Ends Objectives & \\
\hline (Overall) Maximize the value of individual & \\
\hline Secure privacy \& security & Minimize cost \\
Increase safety & Maximize personal freedom \\
Increase personalization & Increase utility \\
$\quad$ individualization & Increase portability \\
Maximize ease of use & \\
\hline Means Objectives & \\
\hline Perform tasks without concerning envi- & Learn my preferences \\
ronment & Increase anonymity \\
Prevent missing information & Make the environment in the way I \\
Receive preferable information & want \\
Receive information appropriate for the & Authenticate users \\
context & Provide multi-purpose functions \\
Lower the device price & Minimize efforts on my side \\
Lower the usage fee & Support where I want \\
Make devices more robust & Support when I want \\
Make devices easy to use & Provide choice for personal prefer- \\
Make devices with minimum options & ence \\
Allow free entry and exit from ubiqui- & Support personal privacy \\
tous environment & Provide educational impact \\
Increase the variety of alternatives & Provide accurate service for me \\
Help personal management & Save time \\
Increase planning ability & Support decision making \\
\hline
\end{tabular}


Establish means-ends network. As a next step of framing values out of the list of objectives, 35 objectives were classified into two categories by analyzing their precedence relations: means objectives and fundamental objectives. The criterion of classification is whether an objective is an intermediate one, i.e. is it a means to achieve another objective or is it a fundamental one in assessing ubiquitous computing. The means objectives, a total of 27 along with 8 fundamental objectives are presented in table 2, respectively. Finally, all objectives are organized in a means-ends relationship diagram using directional relationships. This value framework is presented in Figure 1.

\section{Discussion}

Figure 1 can be interpreted as a framework of values users attach to ubiquitous computing. Objectives on the left side represents means objective which are considered instrumental to achieve ends objectives presented on the right side of the diagram. Among nine ends objectives, "maximize value of individual" seems to be the final fundamental value to which other ends objectives are instrumental to achieve.

From the close inspection of the framework, two points emerges. First, it seems that these objectives can be easily classified using 'five any' typology, which is very popular in ubiquitous computing literature - anybody, any service, any place, any time, and any device [9]. As shown on the left side of figure 1, first three objectives such as 'increase anonymity,' 'help personal management,' and 'authenticate users,' belong to people (anybody) category. As these objectives were collected from users in a bottom-up manner, this fitting confirms that user value system (or the mental model) is familiar with the theoretical model proposed by most ubiquitous computing literature.

Second point is about the progression from left side of the diagram towards the right side: from general to specific or from supply-side view towards demand side view. For example, 'increase anonymity' relates to general notions of anybody while 'secure privacy and security' relates to protection of my rights. It seems that fundamental objectives are mostly concerned with personal specifics while the left-most means objectives refer to more "general" values.

In other words, the perspectives on ubiquitous computing taken by general side are focused on such issues as anybody, anytime, anywhere, any service, and any device and emphases are on: to reach anybody, on the network, any time, anywhere, through any device for any service. However, when you follow the arrow in the framework more toward the fundamental objectives, these values are more concerned with 'to me,' 'right now,' 'here,' 'whatever I need,' and 'on whatever I have.'

These differences in perspective may play an important role in determining requirements for ubiquitous computing business model. For example, 'anybody' requirement can be translated into service universally standardized to different users from the supply-side ("any" side) view, but from the demand-side ("users' side"), it would better be translated as personally customizable service that can be accessed universally. It seems clear that the developers of ubiquitous computing and application need to reconcile these differences in values in order to develop successful technological artifacts which may generate business value which users could buy in. 


\section{Personalization}

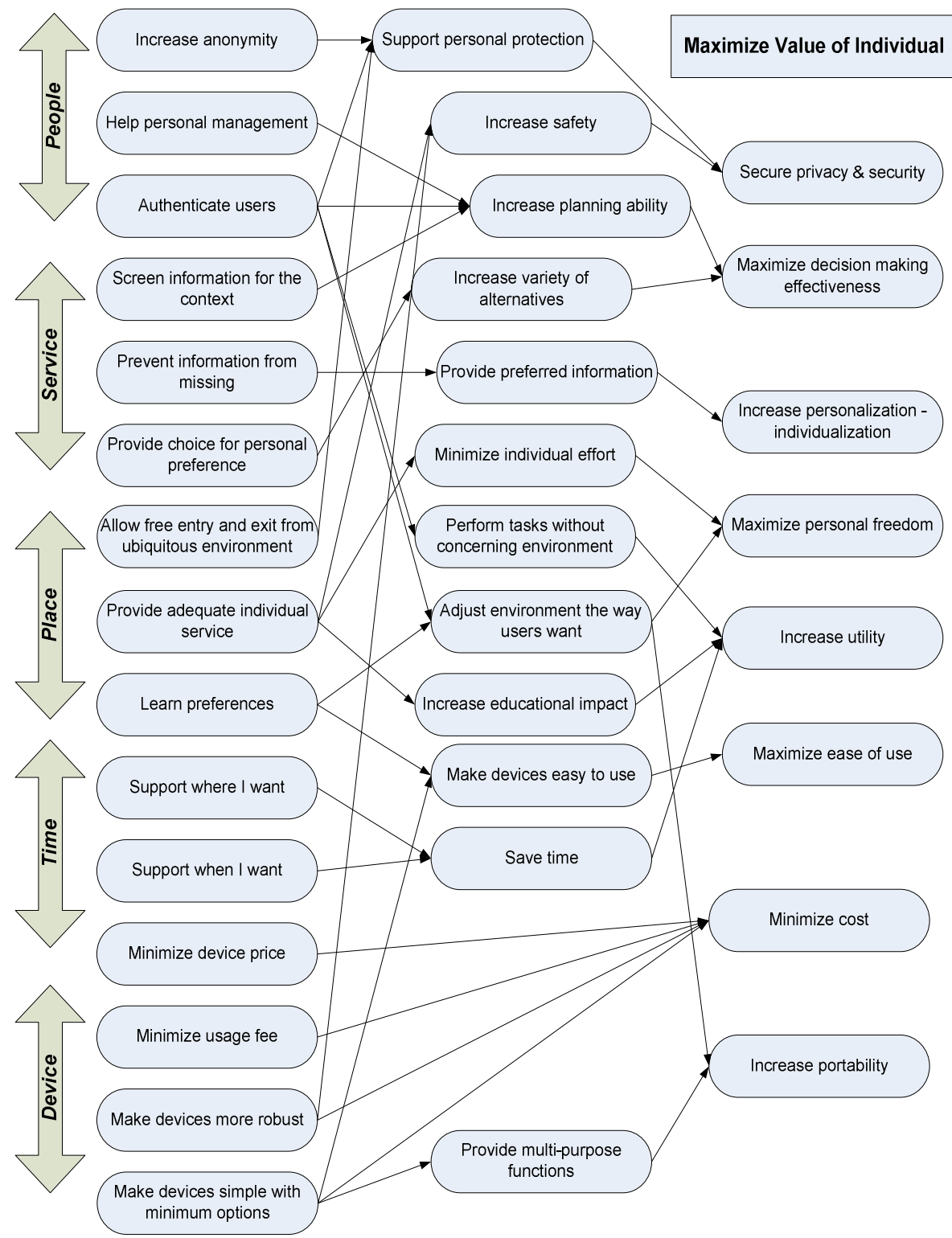

Fig. 1. Means-Ends Network of Values in Ubiquitous Computing 


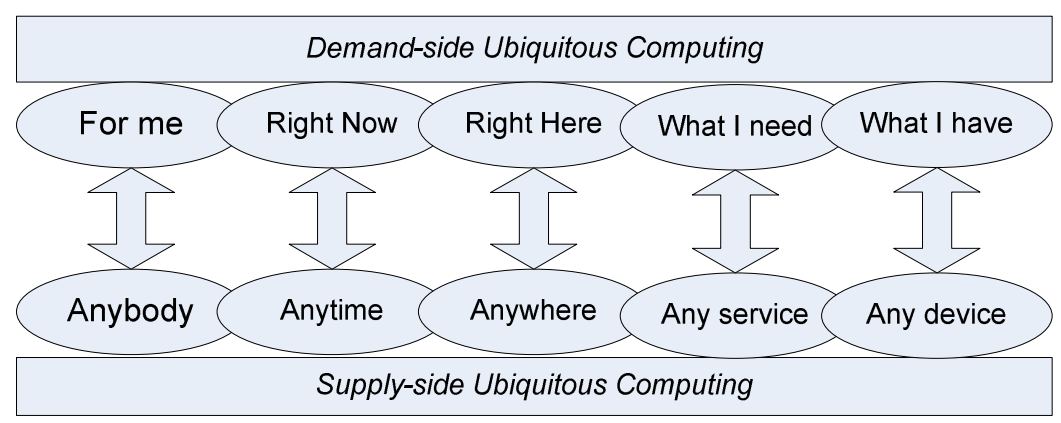

Fig. 2. Reconciliation of Perspectives on Ubiquitous Computing

\section{Conclusion}

Using the notion of ascribing users' values to ubiquitous computing, we are able to develop a value framework that may provide good referential guidelines for technology development as well as new business development with regards to ubiquitous computing. Research presented in this paper identifies a value framework and various propositions that will be a precursor to measure the value of ubiquitous computing, especially in service delivery to users. This instrument is under development.

The value framework proposed here suggests that the progression from supply-side value to demand-side value is an essential problem to be analyzed and solved for successful business model development for ubiquitous computing as well as further development of ubiquitous technology itself.

This study is still in progress. Contradiction underlying the assumptions and belief may deter killer applications to be developed for future ubiquitous computing. It seems important to articulate these contradictions and reconcile them as ubiquitous computing advances. Contradiction dimensions needs further development with supporting theory as well as practical examples. Case studies and scenario analyses would be the next step in revealing implications of these contradictions and interdisciplinary theoretical development should accompany phenomenological observations and experiments.

\section{References}

1. Weiser, M.: The computer of the 21st centry. Scientific American. Vol. 265. No. 3 (1991) 66-75

2. Krishnan, A., S. Jone.: Time Space: activity-based temporal visualization of personal information spaces. Personal Ubiquitous Computing. Vol. 9. No. 1 (2005) 45-65

3. May, A.J., Ross, T., Bayer, S.H., Tarkiainen, M. J.: Pedestrian navigation aids: information requirements and design implications. Personal Ubiquitous Computing. Vol. 7. No. 6 (2003) 331-338

4. Tamminen, S., Oulasvirta, A. Toiskallio, K. Kankainen, A.: Understanding mobile context. Personal Ubiquitous Computing. Vol. 8. No. 2 (2004) 135-143 
5. Keeney, R.L.: Value-Focused Thinking: A Path to Creative Decision-making. Cambridge, Massachusetts: Harvard University Press (1992)

6. Keeney, R.L.: Creativity in Decision Making with Value -Focused Thinking. Sloan Management Review. Vol. 35. No. 4 (1994) 33-41

7. Keeney, R.L.: The Value of Internet Commerce to the Customer. Management Science. Vol. 45. No. 4 (1999) 533-542

8. Torkzadeh, R., Dhillon, G.: Measuring factors that influence the success of Internet commerce. Information Systems Research. Vol. 13. No. 2 (2002) 187-204

9. Weiser, M., Brown, J.S.: Designing calm technology. PowerGrid, Vol. 1.01 (1996) 